\title{
Closterium Nitzsch ex Ralfs (Desmidiaceae) em um lago artificial urbano, Paraná, Brasil
}

\author{
Jascieli Carla Bortolini ${ }^{1}$, Carina Moresco ${ }^{2}$, Natália Silveira Siqueira ${ }^{2}$, Stefania Biolo ${ }^{2}$ e \\ Norma Catarina Bueno ${ }^{1,3}$
}

Recebido: 18.12.2008; aceito: 30.07.2009

ABSTRACT - (Closterium Nitzsch ex Ralfs (Desmidiaceae) in an urban artificial lake, Paraná State, Brazil). An investigation of the genera Closterium from an artificial lake of Cascavel city, Paraná, Brazil was undertaken. The samples were collected from January/2002 to November/2003, in the lake littoral zone. Seventeen taxa of the genera Closterium were identified, where 13 of them were typical and four of them non-typical varieties. C. cynthia De Notaris var. cynthia, represented 25\% of total samples, followed by C. moniliferum (Bory) Ehrenberg ex Ralfs var. moniliferum (17\%). Taxa such as C. ehrenbergii Meneghini $e x$ Ralfs var. ehrenbergii, C. leibleinii Kützing ex Ralfs var. leibleinii e C. lunula (Müller) Nitzsch ex Ralfs var. biconvexum Schmidle were less frequent in the analysis representing $3 \%$ of the taxon total records.

Key words: Desmids, taxonomy, Zygnemaphyceae

RESUMO - (Closterium Nitzsch ex Ralfs (Desmidiaceae) em um lago artificial urbano, Paraná, Brasil). Foi realizado um inventário das espécies do gênero Closterium do lago Municipal de Cascavel, Paraná, Brasil. As coletas foram realizadas entre janeiro de 2002 a novembro de 2003, na região litorânea do lago. Dezessete táxons pertencentes ao gênero Closterium foram identificados, sendo 13 variedades típicas e quatro não típicas de suas espécies. A espécie mais representativa no estudo foi C. cynthia De Notaris var. cynthia, registrado em 25\% das amostras, seguido de C. moniliferum (Bory) Ehrenberg ex Ralfs var. moniliferum registrado em 17\% das amostras. Espécies como C. ehrenbergii Meneghini ex Ralfs var. ehrenbergii, C. leibleinii Kützing ex Ralfs var. leibleinii e C. lunula (Müller) Nitzsch ex Ralfs var. biconvexum Schmidle foram menos freqüentes durante a análise das amostras representando $3 \%$ do registro total dos táxons.

Palavras-chave: Desmídeas, taxonomia, Zygnemaphyceae

\section{Introdução}

Aclasse Zygnemaphyceae constitui um importante grupo em função da alta diversidade morfológica comparada com os demais grupos de algas verdes (Wehr \& Sheat 2003).

A família Desmidiaceae, por sua vez, destaca-se por englobar a grande maioria dos representantes da classe, compondo uma grande variedade de formas e estruturas (Carter-Lund \& Lund 1995, Esteves 1998). Closterium Nitzsch ex Ralfs compreende um gênero rico em número de espécies, incluindo indivíduos solitários e sem constrição mediana (Bicudo \& Castro 1994, Bicudo \& Menezes 2006). Podem apresentar células morfologicamente diferentes, como por exemplo, pólos que variam desde arredondados até capitulados. Outras características como parede celular lisa ou estriada, tipo de cloroplasto, quantidade e distribuição dos pirenóides constituem elementos importantes na identificação das espécies (Bicudo \& Menezes 2006).

Para o estado do Paraná, os seguintes trabalhos compreendem importantes contribuições para o conhecimento das desmídeas: Bittencourt-Oliveira (1993a, b) estudou o Rio Tibagi, principal afluente do Rio Paranapanema, no nordeste do estado, apresentando no primeiro os gêneros filamentosos de desmídeas e no segundo, os gêneros Actinotaenium, Cosmarium e Staurodesmus; em seguida BittencourtOliveira \& Mecenas (1994) fizeram o levantamento taxonômico de Micrasterias, Staurastrum X Xanthidium para o mesmo local; Cecy (1993) documentou para a região de Paranaguá, em uma área de restinga, nove expressões morfológicas de Pleurotaenium eherenbergii (Bréb) De Bary; Cecy et al. (1997) ao estudarem a divisão Chlorophyta da Represa do Rio

1. Universidade Estadual do Oeste do Paraná, CCBS, Rua Universitária 2069, Jd. Universitário, 85819-110 Cascavel, PR, Brasil

2. Universidade Estadual de Maringá, Departamento de Biologia, Nupélia, Av. Colombo, 5790, 87020-900 Maringá, PR, Brasil

3. Autor para correspondência: ncbueno@unioeste.br 
Passaúna, município de Araucária, inventariaram 40 táxons, destes, apenas quatro pertenciam a Closterium; Picelli-Vicentim et al. (2001) realizaram um levantamento do fitoplâncton no mesmo local e registraram 21 táxons de desmídeas, no entanto, nenhum pertencente ao gênero Closterium; Silva \& Cecy (2004) encontraram 20 táxons de Cosmarium, no Rio Iguaçu, região da usina hidrelétrica de Salto Caxias; Biolo et al. (2008) documentaram 41 táxons de desmídeas para o rio São Francisco Falso, tributário do reservatório de Itaipu, na região oeste do estado, contudo, apenas três representantes de Closterium foram apresentados; Felisberto \& Rodrigues (2008) em estudos no reservatório de Salto do Vau, na bacia hidrográfica do Rio Iguaçu registraram a ocorrência de 45 representantes de desmídeas.

Apenas dois trabalhos exclusivamente taxonômicos registraram a ocorrência do gênero Closterium Nitzsch ex Ralfs para o Estado do Paraná: Bittencourt-Oliveira \& Castro (1993) documentaram 21 táxons para o Rio Tibagi e Felisberto \& Rodrigues (2007) 23 táxons para o reservatório de Salto do Vau. Alguns estudos como o de Felisberto (2003), Cetto et al. (2004), Felisberto \& Rodrigues (2005) e Algarte et al. (2006) também reportaram a ocorrência do gênero, todavia, apenas em listagens de caráter ecológico.

$\mathrm{O}$ presente estudo caracteriza o levantamento taxonômico do gênero Closterium no lago Municipal de Cascavel, visando contribuir para o aumento do conhecimento e distribuição da desmidioflórula no estado do Paraná.

\section{Material e métodos}

O Lago Municipal de Cascavel $\left(24^{\circ} 82^{\prime} \mathrm{S}, 53^{\circ}\right.$ $28^{\prime} \mathrm{W}$ ) é um reservatório artificial que juntamente com o Jardim Zoológico formam o Parque Paulo Gorski. O lago está inserido na bacia hidrográfica do rio Cascavel (figura 1), abastecido por vários córregos, com área de drenagem de $117,50 \mathrm{~km}^{2}$. Localiza-se em clima subtropical úmido, mesotérmico e sem estação seca definida (ITCF 1990).

As coletas do material biológico foram realizadas mensalmente, no período de janeiro de 2002 a novembro de 2003, na região litorânea do lago. Utilizou-se rede de plâncton com malha de $25 \mu \mathrm{m}$ para a coleta do material, o qual foi imediatamente conservado em solução Transeau, na proporção 1:1 (Bicudo \& Menezes 2006). Para as análises qualitativas foram preparadas lâminas temporárias, em média de 8 a 10 lâminas por amostra ou até não ocorrer táxons diferentes. A análise das lâminas e as ilustrações foram realizadas com microscópio binocular acoplado à câmara clara, em aumentos de 400 e 1.000 ×. As amostras estão depositadas no Herbário da Universidade Estadual do Oeste do Paraná (UNOP). A identificação dos táxons foi baseada em literaturas clássicas e especializadas e o enquadramento sistemático seguiu Bicudo \& Menezes (2006). As medidas (em $\mu \mathrm{m}$ ) estão representadas pelos símbolos: compr. $=$ comprimento e larg. $=$ largura.

\section{Resultados e Discussão}

A análise das amostras coletadas no Lago Municipal de Cascavel no período de estudo permitiu a identificação de 17 táxons do gênero Closterium Nitzsch ex Ralfs, sendo 13 variedades típicas e quatro variedades não típicas de suas espécies. A espécie melhor representada no estudo foi $C$. cynthia var. cynthia, registrado em $25 \%$ das amostras, seguido de $C$. moniliferum var. moniliferum registrado em $17 \%$ das amostras. Espécies como C. ehrenbergii var. ehrenbergii, C. leibleinii var. leibleinii e C. lunula var. biconvexum foram menos freqüentes durante a análise das amostras totalizando $3 \%$ do registro total dos táxons.

\section{Closterium Nitzsch ex Ralfs}

O gênero Closterium Nitzsch ex Ralfs pode apresentar indivíduos com células lunadas, semilunadas, elípticas ou fusiformes, com a margem dorsal sempre convexa e a ventral reta, côncava, convexa e às vezes inflada na região mediana . Algumas espécies podem apresentar as margens quase paralelas. Os pólos celulares podem ser arredondados, obtuso-arredondados, cônicos, acuminados, obtusos ou ainda capitulados. A parede celular pode ser lisa, estriada ou pontuada. Ocorre apenas um cloroplasto axial por semicélula. Os pirenóides podem ocorrer de um a muitos, em série mediana ou espalhados no cloroplasto. Pode ocorrer também vacúolo terminal com vários corpúsculos trepidantes.

Closterium baillyanum (Brébisson) Brébisson var. baillyanum, Mém. Soc. Imp. Sci. Nat. Cherbourg. 4: 151.1856 Elosterium didymotocum Ralfs var. baillyanum Brébisson in Ralfs, Brit. Desm.: 169. 1848.

Figura 2

Célula ligeiramente curvada, 10-12 vezes mais longa que larga, margem dorsal ligeiramente convexa, 


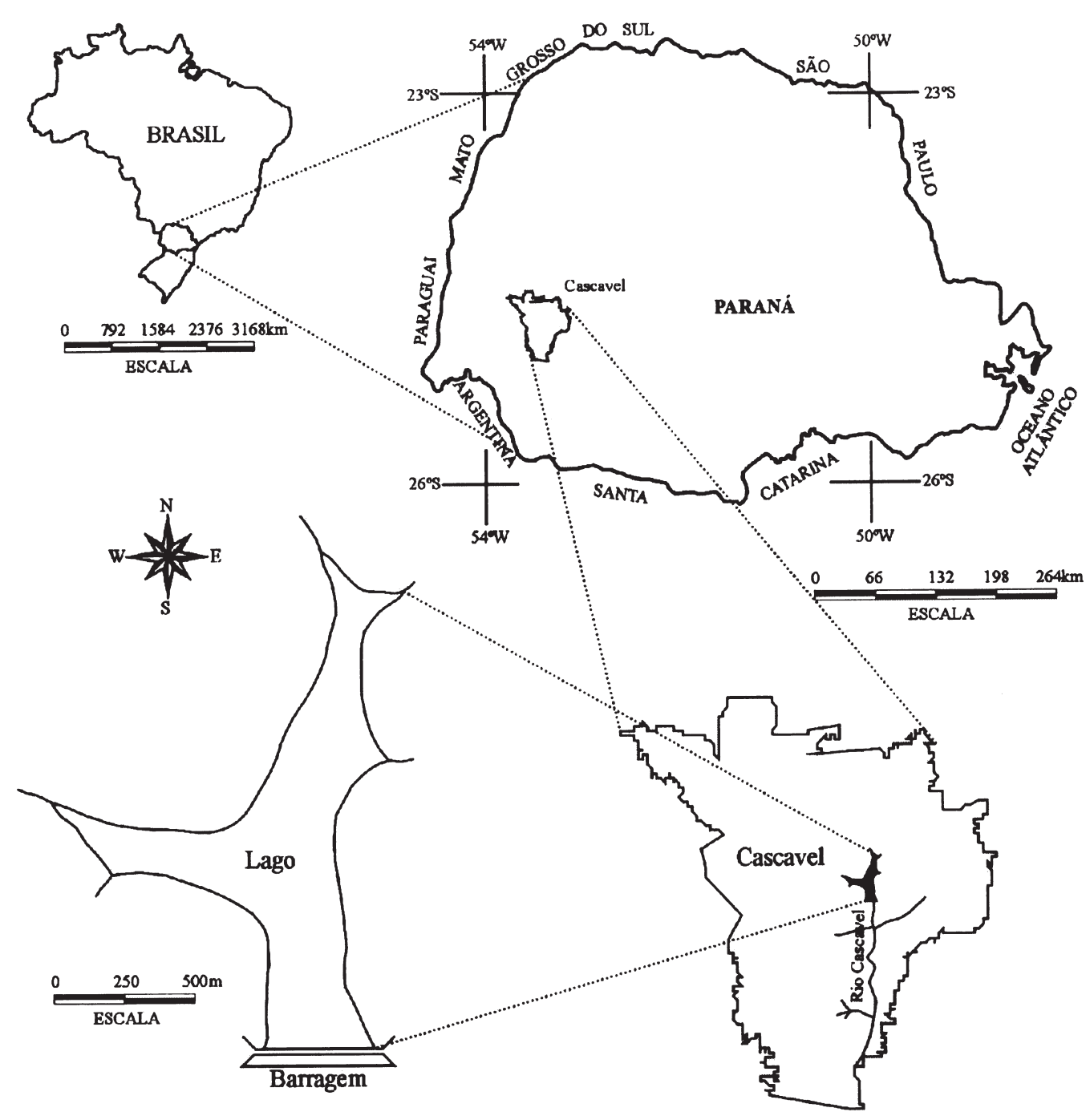

Figura 1. Localização do Lago Municipal de Cascavel, Paraná, Brasil.

Figure 1. Location of the Cascavel Municipal Lake, Paraná, Brazil.

ventral pouco côncava, às vezes mais reta na porção mediana, ápices truncados, parede celular com finas estrias e densas pontuações principalmente na região apical, cloroplasto axial, pirenóides 5-6 dispostos em série mediana, vacúolo terminal e corpúsculos trepidantes não observados. Compr.: 504-588 $\mu \mathrm{m}$; larg.: 44,1-54,6 $\mu \mathrm{m}$.

Material examinado: BRASIL. PARANÁ: Cascavel, Lago Municipal, 26-I-2003, N.C.Bueno 810 (UNOP); idem, 31-VIII-2003, N.C. Bueno 869 (UNOP); idem, 28-IX-2003, N.C. Bueno 878 (UNOP).

A primeira citação de Closterium baillyanum para o Brasil consta no trabalho de Scott, Gronblad
\& Croasdale (1965) para o Estado do Pará, os autores apresentaram medidas e ilustrações das espécies estudadas. Posteriormente Bicudo \& Castro (1994) registraram $C$. baillyanum var. baillyanum para várias localidades do Estado de São Paulo. Os autores registraram polimorfismo celular, e os espessamentos polares apical e lateral da face interna da parede celular, ora faziam-se presentes ora não.

Lopes \& Bicudo (2002) registraram a espécie para o Estado do Amazonas, os organismos identificados apresentaram medidas celulares inferiores às registradas no presente trabalho $(298-310 \times 25-28 \mu \mathrm{m})$. A espécie pode ser facilmente confundida com $C$. abruptum W. West var. canadense Bourrely, porém 
esta espécie apresenta espessamento polar somente na região apical, enquanto $C$. baillyanum var. baillyanum apresenta espessamento polar apical e lateral.

Closterium cornu Ehrenberg ex Ralfs var. cornu, Brit. Desm.: 176. 1848.

Figura 3

Célula semi-lunada, ligeiramente curvada, 12 vezes mais longa que larga, margem dorsal convexa, margem ventral reta, às vezes levemente côncava, não inflada na região mediana, pólos truncados, parede celular lisa, sem espessamento polar, cloroplasto axial, pirenóides 2-5 dispostos em série mediana, vacúolo terminal presente. Compr,: 152,7-193,6 um; larg.; 12,3-12,5 $\mu \mathrm{m}$.

Material examinado: BRASIL. PARANÁ: Cascavel, Lago Municipal, 30-XI-2002, N.C. Bueno 795 (UNOP).

A espécie foi facilmente reconhecida como Closterium cornu var. cornu, por apresentar margem dorsal convexa, pólos truncados e parede celular lisa. Os indivíduos analisados apresentaram margem ventral levemente côncava, enquanto em Bicudo \& Castro (1994) os espécimes analisados apresentaram margem ventral ora reta ora levemente côncava.

Closterium closterioides (Ralfs) Louis \& Peeters var. closterioides, Bull. Jard. bot. natn. Belg. 37: 410. 1967 = Penium closterioides Ralfs, Brit. Desm.: 152. 1848 .

Figura 4

Célula reta, elíptica a fusiforme, 4-4,2 vezes mais longa que larga, margens dorsal e ventral igualmente convexas, pólos arredondado-truncados, parede celular lisa, incolor, cloroplasto axial não dividido transversalmente, cristas 4-5, pirenóides 3-5 em série mediana. Compr,: 126-252 um; larg.: 25,2-67,2 um.

Material examinado: BRASIL. PARANÁ: Cascavel, Lago Municipal, 24-II-2002, N.C.Bueno 734 (UNOP); idem, 25-VIII-2002, N.C. Bueno774 (UNOP); idem 27-X-2002, N.C. Bueno786 (UNOP); idem, 28-VI2003, N.C. Bueno 842 (UNOP).

Closterium closterioides var. closterioides pode ser confundido com $C$. navicula (Bréb.) Lütk.var. navicula e distinguindo-se desta, por apresentar medidas celulares maiores. Na literatura as medidas celulares da espécie variam de 154-179 $\mu \mathrm{m} \times$ 37-45 $\mu \mathrm{m}$ para Bicudo \& Castro (1994); 155-186 um $\times 38-45$ $\mu \mathrm{m}$ para Lopes \& Bicudo (2002) e 147,6 $\mu \mathrm{m} \times 36,7$ $\mu \mathrm{m}$ para Felisberto \& Rodrigues (2007).

Closterium closterioides (Ralfs) Louis \& Peeters var. intermedium (Roy \& Bisset) Růžička, Preslia 45: $1973 \equiv$ Penium libellula (Focke) Nordstedt var. intermedium Roy \& Bisset, Ann. Scot. nat. Hist. 14(12): 252. 1894.

Figura 5

Célula relativamente curta e reta, 2-4 vezes mais longa que larga, margens igualmente convexas, pólos arredondados a truncados, parede celular lisa, cloroplasto laminar interrompido mais ou menos a cada metade da semi-célula, pirenóides 10-12 dispostos em série mediana. Compr.: 77,7-112 $\mu \mathrm{m}$; larg.: 27-27,3 $\mu \mathrm{m}$.

Material examinado: BRASIL. PARANÁ: Cascavel, Lago Municipal, 27-X-2002, N.C. Bueno 786 (UNOP); idem 31-VIII-2003, N.C. Bueno 869 (UNOP).

Closterium closterioides var. intermedium difere de sua variedade típica por apresentar medidas celulares menores e cloroplastídio divididos as vezes transversalmente. Bicudo \& Castro (1994) registraram medidas celulares maiores $(96-151 \mu \mathrm{m} \times 18-32 \mu \mathrm{m})$ e menor número de pirenóides (2-4 por cloroplasto).

Closterium cynthia De Notaris var. cynthia, Desm. Ital.: 65.71. 1867.

Figura 6

Célula lunada, fortemente curvada, 5-7 vezes mais longa que larga, margem dorsal convexa e ventral côncava, podendo às vezes ser levemente inflada na região mediana, pólos arredondados a obtusoarredondados, parede celular estriada, cloroplasto axial, pirenóides 5-7 dispostos em série mediana, corpúsculo trepidante presente. Compr.: 142-165um; larg.: 23,4-29,4 $\mu \mathrm{m}$.

Material examinado: BRASIL. PARANÁ: Cascavel, Lago Municipal, 29-IX-2002, N.C. Bueno 780 (UNOP); idem, 27-X-2002, N.C.Bueno 786 (UNOP); idem 26-I-2003, N.C. Bueno 810 (UNOP); idem, 31VIII-2003, N.C. Bueno 869 (UNOP); idem, 28-IX2003, N.C. Bueno 878 (UNOP); idem, 02-XI-2003, N.C. Bueno 893 (UNOP).

Felisberto \& Rodrigues (2007) registraram valores (125-167 $\mu \mathrm{m}$ compr. $\times 15-24 \mu \mathrm{m}$ larg.) inferiores com relação à largura da célula, porém as medidas do comprimento celular foram mantidas quando 
comparadas com dados de literatura. C. cynthia var. cynthia assemelha-se a $C$. jenneri Ralfs var. jenneri, no entanto, $C$. cynthia var. cynthia apresenta menor arco de curvatura, parede celular sempre estriada e um único corpúsculo trepidante.

Closterium dianae Ehrenberg ex Ralfs var. brevius (Petkov) Krieger in Rabenhorst, KryptogamenFl. Deutschl. 13: 296. 1937 = Closterium dianae Ehrenberg ex Ralfs f. brevius Petk., Philipp. Acad. Bulg. Sci. 1910: 160. 1910.

Figura 7

Célula lunada, 6,2-7,8 vezes mais longa que larga, curvatura acentuada, margem ventral côncava, margem dorsal convexa, pólos oblíquo-truncados com um poro na margem dorsal, parede celular lisa e incolor, espessamento apical presente, cloroplasto axial, pirenóides 3-5 dispostos em série mediana, vacúolo terminal. Compr.: 92,4-115,5 $\mu \mathrm{m}$; larg.: $14,7 \mu \mathrm{m}$.

Material examinado: BRASIL. PARANÁ: Cascavel, Lago Municipal, 28-VI-2003, N.C. Bueno 842 (UNOP); idem, 31-VIII-2003, N.C. Bueno 869 (UNOP).

Closterium dianae var. brevius difere da forma típica da espécie por possuir dimensões celulares menores, por apresentar a porção mediana da célula levemente inflada e parede celular lisa.

Closterium ehrenbergii Meneghini ex Ralfs var. ehrenbergii, Brit. Desm.: 166. 1848.

Figura 8

Célula lunada, 5,5 vezes mais longa que larga, fortemente curvada, margem dorsal convexa, margem ventral côncava, inflada na região mediana, pólos arredondados, parede celular lisa, e cloroplasto axial, cristas 3-4, vários pirenóides espalhados e vacúolo terminal presente. Compr.: 220,5-228,9 $\mu \mathrm{m}$; larg.: 39,3-39,9 $\mu \mathrm{m}$.

Material examinado: BRASIL. PARANÁ: Cascavel, Lago Municipal, 30-XI-2002, N.C. Bueno 795 (UNOP); 2-XI-2003, N.C. Bueno 893 (UNOP).

Closterium ehrenbergii var. ehrenbergii assemelha-se a C. moniliferum (Bory) Ehrenberg ex Ralfs var. moniliferum diferindo por apresentar os pirenóides espalhados pelo cloroplasto. Sophia et al. (2005) registraram a espécie para o Rio Grande do Sul, porém com medidas celulares muito maiores (500-600 $\mu \mathrm{m} \times 90-100 \mu \mathrm{m})$. As medidas celulares registradas no presente trabalho corroboram às medidas obtidas em Lopes \& Bicudo (2002).

Closterium incurvum Brébisson var. incurvum, Mém. Soc. Imp. Sci. Nat. Cherbourg 4: 150. 47. 1856.

Figura 9

Célula lunada, fortemente curvada, 6-8 vezes mais longa que larga, margem dorsal fortemente convexa, ventral côncava, pólos acuminados a acuminado-arredondado, parede celular incolor e lisa com espessamento apical, cloroplasto axial, pirenóides 2-4 dispostos em série mediana, corpúsculos trepidantes presentes. Compr.: 81,9-86,1 $\mu \mathrm{m}$; larg.: 10,5-12,6 $\mu \mathrm{m}$.

Material examinado: BRASIL. PARANÁ: Cascavel, Lago Municipal, 29-IX-2002, N.C. Bueno 780 (UNOP); idem, 27-X-2002, N.C. Bueno 786 (UNOP).

Closterium incurvum var. incurvum assemelha-se a C. venus Kutzing ex Ralfs var. incurvum diferindo desta última por apresentar maior curvatura celular e os pólos acuminado-arredondados. Biolo et al. (2008) registraram o táxon para um tributário do Reservatório de Itaipu, Paraná.

Closterium intermedium Ralfs var. intermedium, Brit. Desm. 171. 1848.

Figura 10

Célula quase reta, 10-14 vezes mais longa que larga, levemente curvada, margem dorsal pouco convexa, margem ventral quase reta, levemente inflada na região mediana, pólos truncados nunca capitulados, parede celular estriada, estrias 6-8 em $10 \mu \mathrm{m}$, com espessamento polar, cloroplasto axial, pirenóides 6-8 em série mediana. Comp.; 210-294 $\mu \mathrm{m}$; larg.: 18,9-21 $\mu \mathrm{m}$.

Material examinado: BRASIL. PARAná: Cascavel, Lago Municipal, 30-XI-2002, N.C. Bueno 795 (UNOP).

Closterium intermedium var. intermedium é semelhante a C. striolatum Ehrenberg var. striolatum, diferindo deste último por apresentar os pólos truncados, não ocorrer pontuações entre as estrias e a região apical nunca ser pontuada, enquanto que em $C$. striolatum var. striolatum os pólos celulares são arredondado-truncados, ocorrendo presença de pontuações entre as estrias e a região celular apical pontuada. 

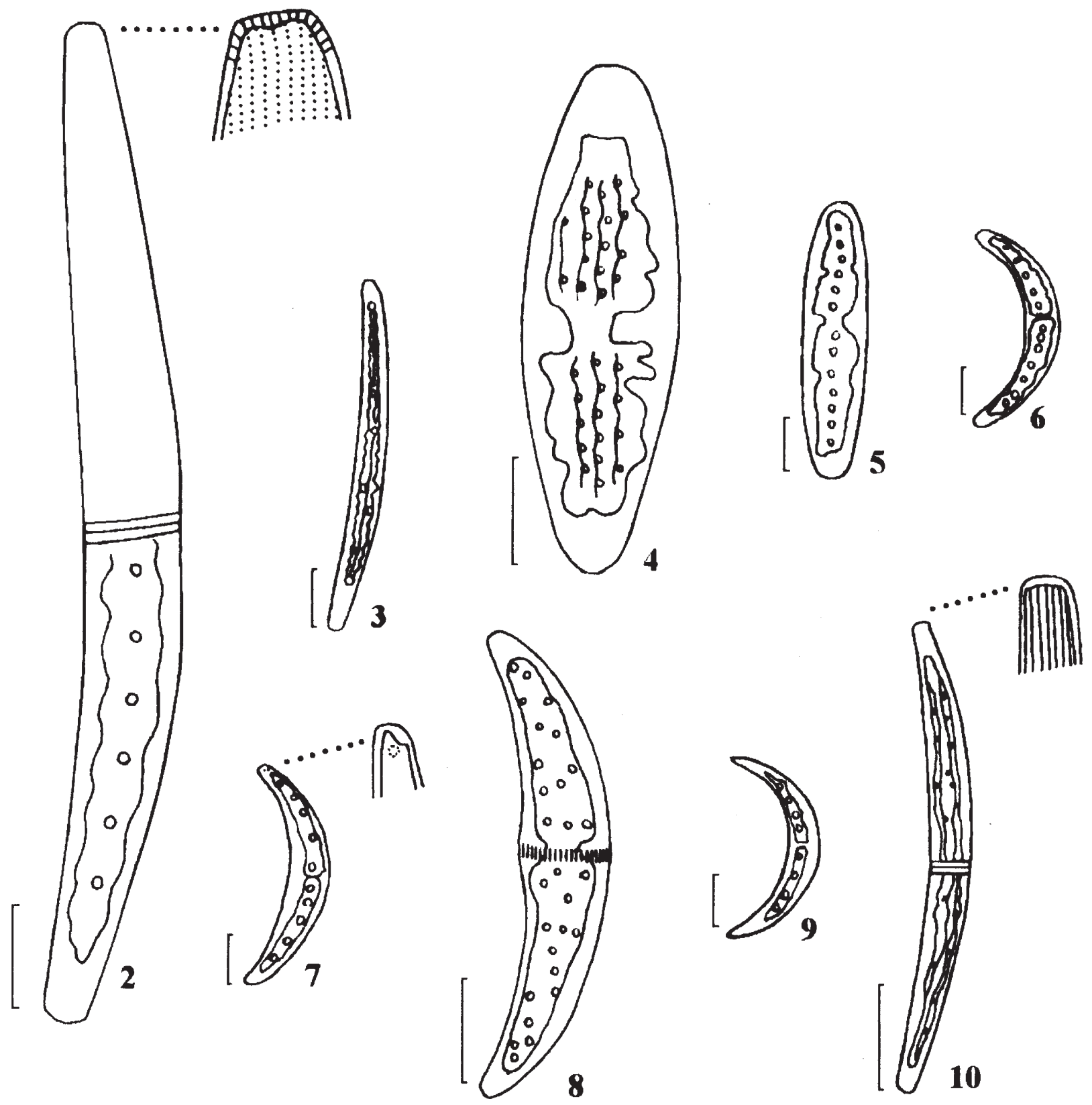

Figura 2-10. Espécies de Closterium do Lago Municipal de Cascavel, Paraná, Brasil. 2. Closterium baillyanum var. baillyanum. 3. Closterium cornu var. cornu. 4. Closterium closterioides var. closterioides. 5. Closterium closterioides var. intermedium. 6. Closterium cynthia var. cynthia. 7. Closterium dianae var. brevius. 8. Closterium ehrenbergii var. ehrenbergii. 9. Closterium incurvum var. incurvum. 10 . Closterium intermedium var. intermedium. Barras $=50 \mu \mathrm{m}: 2,4,8,10 ; 25 \mu \mathrm{m}: 3,5,6,7,9$.

Figures 2-10. Species of Closterium of the Cascavel Municipal Lake. Paraná, Brazil. 2. Closterium baillyanum var. baillyanum. 3 . Closterium cornu var. cornu. 4. Closterium closterioides var. closterioides. 5. Closterium closterioides var. intermedium. 6. Closterium cynthia var. cynthia. 7. Closterium dianae var. brevius. 8. Closterium ehrenbergii var. ehrenbergii. 9. Closterium incurvum var. incurvum. 10 . Closterium intermedium var. intermedium. Scale bars $=50 \mu \mathrm{m}: 2,4,8,10 ; 25 \mu \mathrm{m}: 3,5,6,7,9$. 
Closterium leibleinii Kützing ex Ralfs var. leibleinii, Brit. Desm.:167. 1848.

Figura 11

Célula lunada, 7,8-8,6 vezes mais longa que larga, fortemente curvada, margem dorsal convexa, margem ventral côncava, inflada na região mediana, pólos acuminado-arredondados, parede celular lisa, espessamento polar, cloroplasto axial, pirenóides 5-7 dispostos em série mediana. Compr.: 163,8-280,6 um; larg.: 21-23,1 $\mu \mathrm{m}$.

Material examinado: BRASIL. PARANÁ: Cascavel, Lago Municipal, 31-VIII-2003, N.C. Bueno 869 (UNOP).

Closterium leibleinii var. leibleinii assemelhase a $C$. dianae Ehrenberg ex Ralfs var. dianae f. dianae, entretanto, esta última espécie apresenta pólos obtuso-arredondados e maior proporção comprimento/ largura, enquanto que em C. leibleinii var. leibleinii os pólos são acuminado-arredondados e a proporção comprimento/largura é menor. Observou-se durante a análise qualitativa das amostras que a espécie apresentou maior comprimento que a já documentado por Felisberto \& Rodrigues (2007) para o estado do Paraná (137-158,4 $\mu \mathrm{m})$.

Closterium lunula (Müller) Nitzsch ex Ralfs var. biconvexum Schmidle, Oster. Bot. 2. 45: 309. 1895.

Figura 12

Célula pouco curvada, quase reta, 3-4, 1 vezes mais longa que larga, margem dorsal ligeiramente convexa, margem ventral pouco convexa, às vezes inflada na região mediana, pólos celulares arredondados, parede celular lisa, cloroplasto axial, cristas 4-5, vários pirenóides espalhados, vacúolo terminal. Compr.: 130-142 $\mu \mathrm{m}$; larg.: 34-44 $\mu \mathrm{m}$.

Material examinado: BRASIL. PARANÁ: Cascavel, Lago Municipal, 21-VI-2002, N.C. Bueno 764 (UNOP).

A variedade típica da espécie difere da variedade encontrada por apresentar pólos celulares atenuados e truncados e pela disposição dos pirenóides em série mediana.

Closterium moniliferum (Bory) Ehrenberg ex Ralfs var. moniliferum, Brit. Desm.: 166. 1848 三 Lunulina monilifera Bory, Encycl. Meth. Hist. nat. zoophyt. 2(2): 501.1824.
Figura 13

Célula lunada, fortemente curvada, 4,6-5,4 vezes mais longa que larga, margem dorsal extremamente convexa, ventral côncava, algumas vezes levemente inflada na região mediana, pólos arredondados, parede celular lisa e incolor, cloroplasto axial, pirenóides 6-8 dispostos em série mediana, vacúolo terminal. Compr.: 230-256,2 $\mu \mathrm{m}$; larg.: 42-54,6 $\mu \mathrm{m}$.

Material examinado: BRASIL. PARANÁ: Cascavel, Lago Municipal, 25-VIII-2002, N.C. Bueno 774 (UNOP); idem, 27-X-2002, N.C. Bueno 786 (UNOP); idem, 31-VIII-2003, N.C. Bueno 869 (UNOP); idem, 28-IX-2003, N.C. Bueno 878 (UNOP).

Closterium moniliferum var. moniliferum pode ser confundida com a variedade típica de C. ehrenbergii Meneghini ex Ralfs, diferindo desta pelo maior número e distribuição aleatória dos pirenóides no cloroplasto. Biolo et al (2008) registraram a espécie pela primeira vez na região oeste do estado em um tributário do Reservatório de Itaipu $(183,6-259,1 \mu \mathrm{m}$ $\times 40,8-53,1 \mu \mathrm{m})$.

Closterium navicula (Brébisson) Lütkemuller var. navicula, Beitr. Biol. Pfl. Breslau 8: 395.408. 1902 „Penium navicula Brébisson, Mém. Soc. imp. Sci. nat. Cherbourg 4: 146.37. 1856.

Figura 14

Célula reta, elíptica a fusiforme, 3,1-4 vezes mais longa que larga, margens dorsal e ventral igualmente convexas, pólos arredondado-truncados, parede celular lisa, incolor, cloroplasto axial, cristas 4-5, pirenóides 1-3 dispostos em série mediana. Compr.:

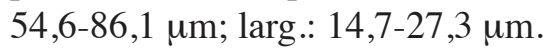

Material examinado: BRASIL. PARANá: Cascavel, Lago Municipal, 24-V-2002, N.C.Bueno 761 (UNOP); idem, 31-VIII-2003, N.C. Bueno 869 (UNOP).

Closterium navicula var. navicula pode ser confundida com C. closterioides (Ralfs) Louis \& Peeters var. closterioides devido a grande semelhança morfológica, porém C. navicula var. navicula apresenta medidas celulares bem menores.

Closterium pusillum Hantzsch var. pusillum, in Rabenhorst, Algae Europ. Exsic.: 1008. 1861.

Figura 15

Célula semilunada, ligeiramente curvada, 4,7-4,8 vezes mais longa que larga, margem dorsal convexa, 
margem ventral quase reta, parede celular lisa, pólos truncado-arredondados, cloroplasto axial, pirenóides 2-3 em série mediana. Compr.: 27,6-39,3 um; larg.: 5,7-8,2 $\mu \mathrm{m}$.

Material examinado: BRASIL. PARANá: Cascavel, Lago Municipal,24-II-2002, N.C.Bueno 734 (UNOP).

Closterium pusillum var. pusillum assemelha-se morfologicamente a C.pygmaeum Gutwinski, difere, porém, pela presença de pólos celulares acuminadoarredondados e pela região mediana da margem ventral sempre côncava.

Bicudo \& Castro (1994) registraram na amostra populacional estudada polimorfismo nos pólos celulares, que ora apresentavam-se arredondados ora arredondado-truncados, a região mediana da margem ventral ora retilínea ora côncava, e em relação ao espessamento polar que ora se fazia presente ora não. A mesma espécie foi registrada por Felisberto \& Rodrigues (2007) para o Reservatório Salto do Vau no Sul do Brasil, porém, as medidas celulares registradas $(43,2-47,6 \mu \mathrm{m} \times 9,6 \mu \mathrm{m})$ pelas autoras foram maiores que para o presente estudo.

Closterium ralfsii Brébisson ex Ralfs var. hybridum, in Rabenhorst, Krypt.-F1. Sachs.: 174. 1863.

Figura 16

Célula ligeiramente curvada, quase reta, 10-12 vezes mais longa que larga, margem dorsal convexa, ventral moderadamente convexa, levemente inflada na região mediana, pólos celulares truncados, parede celular estriada, cloroplasto axial, pirenóides 10-12 dispostos em série mediana. Compr.: 340,2-413,7 $\mu$ m; larg.: 33,6-35,7 $\mu \mathrm{m}$.

Material examinado: BRASIL. PARANÁ: Cascavel, Lago Municipal, 29-IX-2002, N.C. Bueno 780 (UNOP); idem, 27-X-2002, N.C.Bueno 786(UNOP); idem, 30-XI-2002, N.C. Bueno 795 (UNOP); idem, 31-VIII-2003, N.C. Bueno 869 (UNOP).

Closterium ralfsii var. hybridum assemelha-se a variedade típica da espécie, porém a variedade típica apresenta relação comprimento/largura menor. As medidas celulares aqui documentadas aproximam-se das medidas registradas em literatura, como em Felisberto \& Rodrigues (2007) que registraram C. ralfsii var. hybridum na comunidade perifitica do Reservatório de Salto do Vau, sul do Brasil com medidas variando entre 447-489,7 $\mu \mathrm{m} \times 34,9-37,5 \mu \mathrm{m}$.
Closterium setaceum Ehrenberg ex Ralfs var. setaceum, Brit. Desm.: 176. 1848.

Figura 17

Célula fusiforme-lanceolada, 19-21 vezes mais longa que larga, quase reta, margem dorsal e ventral igualmente convexas, sendo a porção mediana fusiforme, pólos truncados, parede celular lisa ou finamente estriada, pouco visível, cloroplasto axial, pirenóides 2-3 em série mediana, processos setáceos

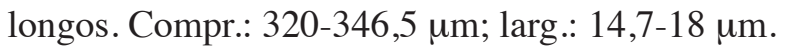

Material examinado: BRASIL. PARANÁ: Cascavel, Lago Municipal, 30-XI-2002, N.C. Bueno 795 (UNOP).

Closterium setaceum var. setaceum difere de C. rostratum var. rostratum em função do maior comprimento celular e maior proporção comprimento/ largura. A espécie já foi registrada no Lago Cristalino e Lago São Sebastião no Amazonas (Martins 1982), para o Estado de São Paulo (Bicudo \& Castro 1994) e para o sul do Brasil (Felisberto \& Rodrigues 2007).

Closterium striolatum Ehrenberg ex Ralfs var. striolatum, Brit. Desm.: 170. 1848.

Figura 18

Célula lunada, 5,7-7 vezes mais longa que larga, margem dorsal convexa, margem ventral levemente côncava, pólos arredondado-truncados, parede celular visivelmente estriada, cloroplasto axial, cristas 3-4, pirenóides numerosos e espalhados. Compr.: 193226,8 um; larg.: 33,6-36 $\mu \mathrm{m}$.

Material examinado: BRASIL. PARAnÁ: Cascavel, Lago Municipal, 27-X-2002, N.C. Bueno 786 (UNOP); idem, 30-XI-2002, N.C.Bueno 795 (UNOP); idem, 31-VIII-2003, N.C. Bueno 869 (UNOP).

Closterium striolatum var. striolatum apresenta estrias na parede celular facilmente observadas, possui ainda semelhança morfológica com $C$. intermedium Ralfs var. intermedium, que possui pólos celulares truncados e ausência de pontuações entre as estrias e na região apical, ao contrário de Closterium striolatum var. striolatum que possui pólos arredondadotruncados e pontuações entre as estrias e na região apical. Bicudo \& Castro (1994) registraram o táxon com medidas celulares superiores (144-428 $\mu \mathrm{m} \times$ 17-44 $\mu \mathrm{m})$ ao contrário de Felisberto \& Rodrigues (2007) que registraram o táxon com medidas inferiores $(132-192 \mu \mathrm{m} \times 12-20 \mu \mathrm{m})$. 

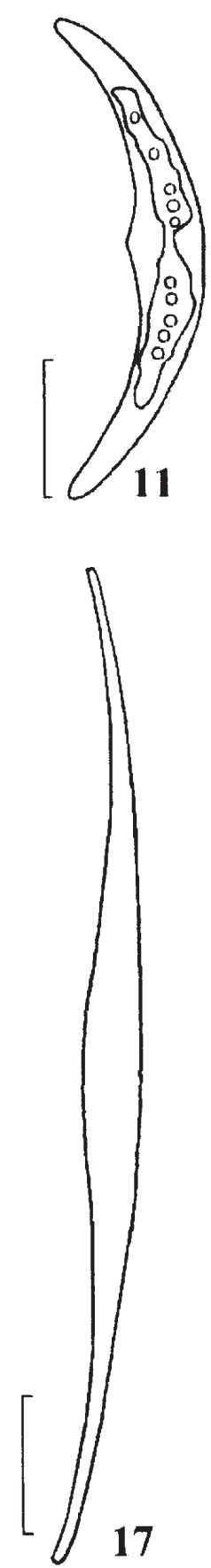

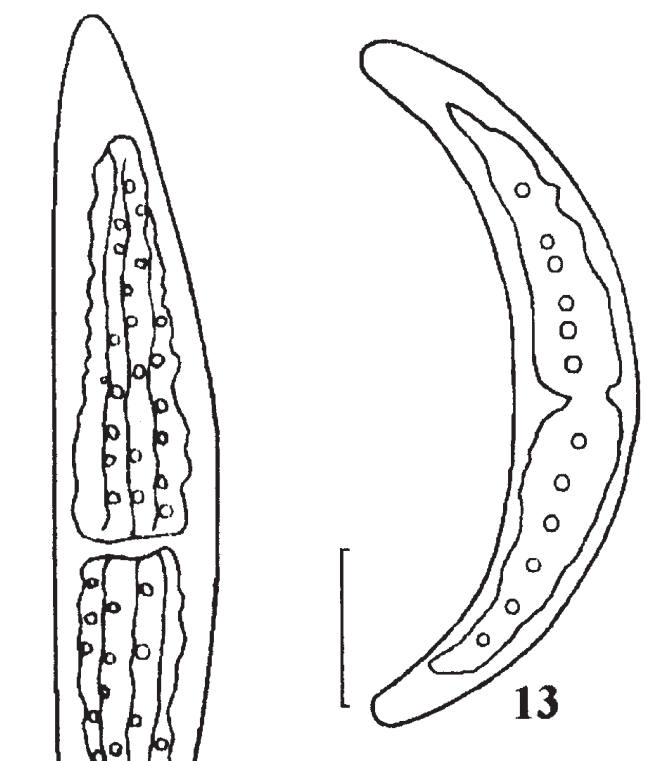

12
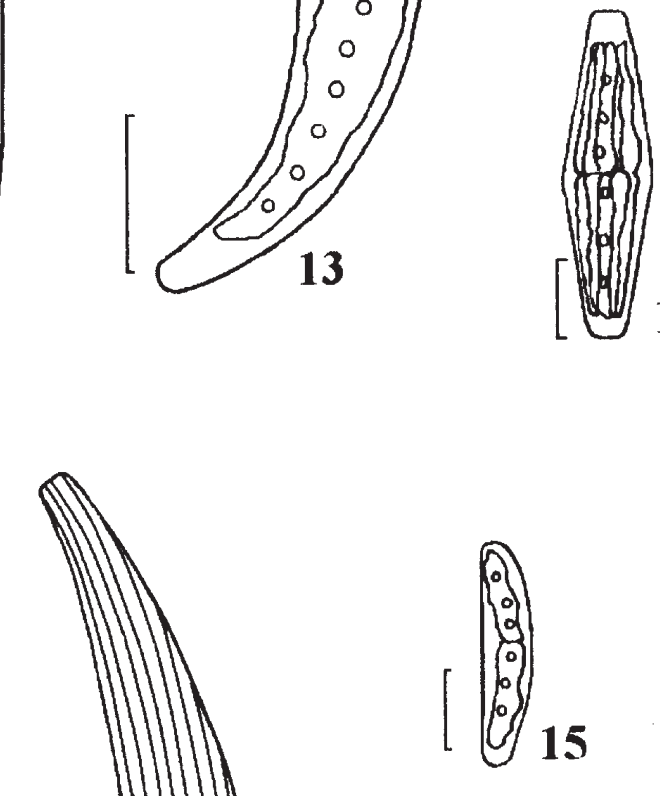

\section{4}

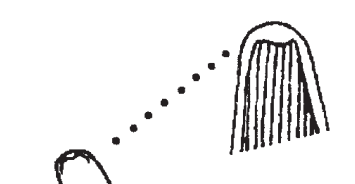

Figuras 11-18. Espécies de Closterium do Lago Municipal de Cascavel, Paraná, Brasil. 11. Closterium leibleinii var. leibleinii. 12. Closterium lunula var. biconvexum. 13. Closterium moniliferum var. moniliferum. 14. Closterium navicula var. navicula. 15. Closterium pusillum var. pusillum.16. Closterium ralfsii var. hybridum. 17. Closterium setaceum var. setaceum. 18. Closterium striolatum var. striolatum. Barras $=50 \mu \mathrm{m}: 11,12,13,16,17,18 ; 25 \mu \mathrm{m}: 14 ; 10 \mu \mathrm{m}: 15$.

Figures 11-18. Species of Closterium of the Cascavel Municipal Lake, Paraná, Brazil. 11. Closterium leibleinii var. leibleinii. 12. Closterium lunula var. biconvexum. 13. Closterium moniliferum var. moniliferum. 14. Closterium navicula var. navicula. 15. Closterium pusillum var. pusillum. 16. Closterium ralfsii var. hybridum. 17. Closterium setaceum var. setaceum. 18. Closterium striolatum var. striolatum. Scale bars $=50 \mu \mathrm{m}: 11,12,13,16,17,18 ; 25 \mu \mathrm{m}: 14 ; 10 \mu \mathrm{m}: 15$. 


\section{Literatura citada}

Algarte, V.M., Moresco, C. \& Rodrigues, L. 2006. Algas do perifíton de distintos ambientes na planície de inundação do alto Rio Paraná. Acta Scientiarium, Biological Sciences 28: 243-251.

Bicudo, C.E.M. \& Castro, A.A.J. 1994. Desmidioflórula paulista IV (gêneros Closterium, Spinoclosterium). J. Cramer, Berlim.

Bicudo, C.E.M.\& Menezes, M. 2006. Gêneros de algas de águas continentais do Brasil. Editora RiMa, São Carlos.

Biolo,S.,Siqueira, N.S.\& Bueno, N.C.2008. Desmidiaceae (exceto Cosmarium) de um tributário do Reservatório de Itaipu, Paraná, Brasil. Hoehnea 35: 309-326.

Bittencourt-Oliveira, M.C. 1993a. Ficoflórula do Rio Tibagi, Estado do Paraná, Brasil I: Desmídias filamentosas e gêneros Gonatozygon, Penium, Pleurotaenium e Tetmemorus (Zygnemaphyceae). Semina, Ciências Biológicas 14: 61-73.

Bittencourt-Oliveira, M.C. 1993b. Ficoflórula do Rio Tibagi, Estado do Paraná, Brasil III: gêneros Actinotaenium, Cosmarium e Staurodesmus (Zygnemaphyceae). Semina, Ciências Biológicas 149: 86-95.

Bittencourt-Oliveira, M.C. \& Castro, A.A.J. 1993 Ficoflórula do Rio Tibagi, Estado do Paraná, Brasil, II: gênero Closterium (Zygnemaphyceae). Semina, Ciências Biológicas 14: 74-85.

Bittencourt-Oliveira, M.C. \& Mecenas, P.R. 1994. Ficoflórula do Rio Tibagi, Estado do Paraná, Brasil, IV: gêneros Micrasterias, Staurastrum e Xanthidium (Zygnemaphyceae). Semina, Ciências Biológicas 15: 133-152.

Carter-Lund, C.H. \& Lund, J.W.G. 1995. Freshwater Algae: their microscopic world explored. Biopress Limited, Bristol.

Cecy, I.I.T. 1993. Expressões morfológicas observadas em Pleurotaenium ehrenbergii (Brébisson) De Bary, procedentes da Restinga de Pontal do Sul, Município de Paranaguá, Paraná. Estudos de Biologia 30: 5-20.

Cecy, I.I.T., Silva, S.R.V. \& Boccon, R. 1997. Fitoplâncton da Represa do Rio Passaúna, Município de Araucária, Estado do Paraná. I - Divisão Chlorophyta - Família Desmidiaceae. Estudos de Biologia 41: 5-32.

Cetto, J.M., Leandrini, J.A., Felisberto, S.A. \& Rodrigues, L. 2004. Comunidade de algas perifíticas no reservatório de Irai, Estado do Paraná, Brasil. Acta Scientiarium, Biological Sciences 26: 1-7.
Esteves, F.A. 1998. Fundamentos de Limnologia. 2 ed Interciência, Rio de Janeiro.

Felisberto, S.A. 2003. Composição e abundância de desmídias perifiticas caracterizando reservatórios e suas regiões ao longo do eixo rio-barragem. Dissertação de Mestrado, Universidade Estadual de Maringá, Maringá.

Felisberto, S.A. \& Rodrigues, L. 2002. Desmidiales (exceto o gênero Cosmarium) perifíticas no reservatório de Corumbá, Goiás, Brasil. Iheringia 57: 75-97.

Felisberto, S.A. \& Rodrigues, L. 2005. Comunidade de algas perifíticas em reservatórios de diferentes latitudes. In: L. Rodrigues, S.M., Thomaz, A.A. Agostinho \& L.C. Gomes (orgs.). Biocenose em reservatórios: padrões espaciais e temporais. RiMa, São Carlos, pp. 97-114.

Felisberto, S.A.\& Rodrigues, L. 2007. Gênero Closterium (Closteriaceae) na comunidade perifítica do reservatório de Salto do Vau, sul do Brasil. Iheringia 62: 45-54.

Felisberto, S.A. \& Rodrigues, L. 2008. Desmidiaceae, Gonatozygaceae e Mesotaeniaceae na comunidade perifitica do reservatório de Salto do Vau (Bacia do rio Iguaçu, PR). Hoehnea 35: 235-254.

ITCF. 1990. Atlas do Estado do Paraná. ITCF/SEAB, Curitiba.

Lopes, M.R.M. \& Bicudo,C.E.M. 2002. Desmidioflórula de um Lago da planície de inundação do Rio Acre, Estado do Amazonas, Brasil. Acta Amazonica 33: 167-212.

Martins, D.V.1982. Desmidioflórula dos lagos Cristalino e São Sebastião, Estado do Amazonas: Gêneros Netrium, Closterium e Pleurotaenium. Acta Amazonica 12: 279-290.

Picelli-Vicentim, M.M., Treuersch, M. \& Domingues, L.L. 2001. Fitoplâncton da Represa do Passaúna, Estado do Paraná, Brasil. Hoehnea 28: 53-76.

Scott, A.M., Grönblad, R. \& Croasdale, H.T. 1965. Desmids from the Amazon Basin, Brazil, collected by Dr. H. Sioli. Acta Botanica Fennica 69: 3-93.

Silva, S.R.V.F. \& Cecy, I.I.T. 2004. Desmídias (Zygnemaphyceae) da área de abrangência da Usina Hidrelétrica de Salto Caxias, Paraná, Brasil, I: Gênero Cosmarium. Iheringia 59: 13-26.

Sophia, M.G., Dias, I.C.A. \& Araújo, A.M. 2005 Chlorophyceae and Zygnematophyceae from the Turvo State Forest Park, state of Rio Grande do Sul, Brazil. Iheringia 60: 25-47.

Wehr, J.D.\& Sheat, R.G.2003. Freshwater algae of North America: Ecology and classification. Academic Press, New York. 